\title{
FAIR TRADE, 30 ANOS: UM SONHO DESFEITO?
}

Armando de Melo Lisboa

Professor da Universidade Federal de Santa Catarina

\section{Resumo}

Examinando o surgimento das redes de comercio justo a partir do seu berço com os índios mexicanos, o texto discute os limites desta modalidade de comércio diante do capitalismo global.

\section{Palavras-chave}

Fair trade. Solidariedade. Comércio justo.

\section{FAIR TRADE, 30 YEARS: A BROKEN DREAM?}

\section{Abstract}

Examining the rise of fair trade networks from their cradle among the Mexican natives, the article discusses the limits of this type of trade on global capitalism.

Keywords

Fair trade. Solidarity. Fair trade.

En la encrucijada actual, solo las utopías parecen posibles. Lo único imposible es mantener la trayectoria convencional (Gustavo Esteva).

$\mathrm{O}$ comércio justo $(\mathrm{CJ})^{1}$ mundial como amplamente hoje é conhecido, com utilização de selos de certificação de origem, surgiu há 30 anos através da aliança entre a organização indígena UCIRI (Oaxaca, México), e Solidaridad (agência de ajuda aos países da América Latina dos católicos holandeses). Quando de sua concepção ele possuía uma face radical, assim explicitada (e reatualizada) pelo pioneiro Frans van der Hoff: "éramos e seremos sempre anticapitalistas"

\footnotetext{
1 "Comércio justo" traduz-se nas línguas ocidentais hegemônicas como fair trade, em inglês e alemão; commerce équitable, em francês; commercio equo e solidale, italiano.
} 
(apud Jacquiau, 2007). Cabe inscrever o CJ como parte de um movimento maior de reconstrução da organização econômica em termos diferenciados da capitalista, e que alguns denominam de "economia solidária". Todavia, o que hoje se denomina fair trade há muito deixou de ser uma prática restrita a organizações alternativas, tendo uma significativa amplitude no cenário econômico global. Em face das esperanças depositadas, e da pluralidade de atores que configuram o movimento do $\mathrm{CJ}$, em seu seio inúmeros questionamentos são feitos e permanecem abertos:

a) Produz o CJ uma equidade maior nas relações Norte-Sul, corrige a assimetria nos intercâmbios entre países desenvolvidos e em desenvolvimento?

b) Supera o CJ a divisão internacional do trabalho onde o Sul fornece matérias-primas e produtos agrícolas para exportação aos países ricos, e o Norte é produtor industrial e detém o principal mercado de consumo de massa?

c) Permite o CJ a re-humanização dos processos comerciais (e da economia)?

d) Responde o CJ aos desafios ecológicos hoje postos?

e) É possível transformar o capitalismo, modificando-o a partir de dentro? São os mercados fator de transformação social?

\section{BREVE HISTÓRICO}

O CJ surgiu como um movimento de solidariedade Norte-Sul para buscar diminuir os efeitos negativos do comércio internacional. Apresentava-se como uma inovadora via de cooperação internacional fundada numa prática comercial definida por determinados códigos de conduta.

Nos seus primórdios, o CJ configurava iniciativas assistenciais, caridosas e políticas que, com base no comércio de produtos do Sul com o Norte em bases mais equitativas, buscavam amenizar a situação de países do Sul (em geral, ex-colônias europeias). Os princípios fundamentais de todo CJ são a obtenção de um preço mais justo e de uma melhor renda para os produtores, e, simultaneamente, fomentar um consumo responsável diferenciado do consumismo dominante.

Um marco inaugural do comércio ético foi a primeira Conferência das Nações Unidas sobre o Comércio e o Desenvolvimento (Unctad), em 1964, onde surge a consigna "trade, not aid!" 
(Comércio, não ajuda), popularizando a expressão comércio alternativo e/ou comércio solidário. Em 1969 abre-se na Holanda a primeira loja de comércio solidário. Nesta primeira fase o CJ está restrito aos circuitos alternativos e a lojas especializadas.

Buscando "modificar radicalmente o esquema do "comércio alternativo" (Hoff, 2004), em 1988 surge a primeira marca registrada do CJ - Max Havelaar ${ }^{2}$ - resultado de uma parceria entre a organização católica holandesa Solidaridad e a UCIRI, associação de produtores de café de índios mexicanos. Isto gera uma revolução quanto ao alcance deste tipo de comercialização, pois permitiu que os produtos do CJ ingressassem nos grandes circuitos comerciais dos países industrializados.

A criação do selo de CJ Max Havelaar foi o grande divisor de águas. Com ele, os produtos do CJ deixam de vendidos exclusivamente em lojas especializadas, passando a serem também distribuídos no mercado convencional. A introdução deste programa de certificação no mercado holandês deu início a um movimento mundial, surgindo outros selos.

A certificação possibilitou a distribuição de produtos da economia solidária, então comercializados nas lojas de CJ, em larga escala. Assim, o movimento do CJ deixou de estar circunscrito a comercialização de produtos de pequenos produtores dos países do Sul, apoiados por consumidores solidários. Foi tal o sucesso que a partir de então a certificação passa a ser elemento central e definidor do CJ. Ou seja, CJ passa a ser identificado como CJ certificado.

Não por acaso, o surgimento deste tipo de CJ se dá na década de 80. Naquela ocasião ocorre a suspensão do Acordo Internacional do Café no que tange à regulamentar os preços, seguido do desmantelamento das organizações que o faziam respeitar, como o INMECAFE, no México, órgão federal de apoio e controle deste setor, liquidado em 1989; e do Instituto Brasileiro do Café (IBC), extinto em 1990. Isto significou que este aromático voltava a ser regulado pelo mercado (ou seja, pelos grandes oligopólios que dominam o mesmo). Reagindo aos mais baixos valores históricos do café que então se seguiram, a inserção do café nas redes de CJ permitiu a sobrevivência de inúmeros pequenos produtores.

A presente onda do CJ irrompe, portanto, durante a maré neoliberal contemporânea, sendo gerada pela mesma, uma vez que o retraimento do Estado do controle da comercialização cafeteira (e outras commodities) abriu espaços para iniciativas comunitárias buscarem melhores condições comerciais. Retomando o lema da UNCTAD (“trade, not aid!”), mas agora à revelia

\footnotetext{
${ }^{2}$ Personagem da literatura holandesa, Max Havelaar é um comerciante que defendeu os pequenos produtores de café na
} Indonésia, outrora colônia holandesa. 
dos fóruns interestatais de negociação internacional, estas inciativas buscaram eliminar intermediários e obter melhores preços através da construção de redes comerciais próprias.

O sucesso do selo holandês (também na França, Bélgica e Suíça) fez surgir na Europa dois outros sistemas de certificação: Fairtrade, na Inglaterra e na Irlanda; e Transfair, na Alemanha e Itália. Porém, as particularidades de cada sistema, cada qual com suas próprias normas, geraram sérios problemas, levando a criação da Fairtrade Labelling Organizations (FLO) em 1997, atualmente Fairtrade International (FI), que passou a coordenar os selos de CJ no mundo. Hoje a FI reúne 22 iniciativas nacionais de certificação, sendo que, após muitas pressões dos organismos do Sul, a partir do final de 2006 sua junta diretiva inclui a participação de três redes continentais de produtores: Fairtrade Africa (anteriormente AFN - African Fairtrade Network); CLAC (Coordinadora Latinoamericana y del Caribe de Comercio Justo) ${ }^{3}$; NAPP (Network of Asia and Pacific Producers).

As lojas e organizações de CJ também se aglutinaram, formando três federações: em 1989 a World Fair Trade Organization (WFTO) ${ }^{4}$, que reúne produtores, lojas, importadores e empresas diversas de CJ; em 1990, a European Fair Trade Association (EFTA), federação dos importadores de comércio justo; e em 1994 a Network of European World Shops (NEWS), que agrupa federações nacionais de lojas. Essas quatro federações estão reunidas através da FINE (sigla formada pelas iniciais de FLO, IFAT, NEWS, EFTA), uma rede informal que busca uma cooperação estratégica entre elas.

Surgindo como um comércio alternativo e solidário, e estando no seu início confinado aos atores da economia solidária, a partir da década de noventa, transmutado em CJ, torna-se um cobiçado mercado emergente, gerando um interesse crescente dos atores do comércio convencional em incluírem produtos de CJ na sua oferta. Tendo um crescimento exponencial nos últimos anos, atualmente os produtos de CJ são comercializados em grandes cadeias de supermercados, existindo inclusive corporações multinacionais que, com marcas próprias, inauguram o CJ corporativo. Apenas na Europa, já em 2005 os produtos de CJ estavam disponíveis em 2.800 Lojas do Mundo, 56.700 supermercados, e em 20.000 locais de venda (organizações sociais, escolas e outros parceiros institucionais ...).

\footnotetext{
${ }^{3}$ A CLAC se constitui em 2004, mas é originária da Coordinadora Latinoamericana y del Caribe de Pequenos Productores de Café, e da PAUAL (Red Latinoamericana de Pequenos Apicultores), ambas fundadas em 1996. Hoje é composta por 300 entidades de pequenos produtores de América Latina e Caribe certificados como CJ, envolvendo 200 mil famílias.

${ }^{4}$ Que até 2008 denominava-se International Federation for Alternative Trade (IFAT).
} 
Hoje o CJ já não tem as modestas dimensões dos anos 70/80. A FI, a maior organização de CJ do mundo, se apresenta como uma rede com 1 milhão e 400 mil produtores de mais de 70 países (FI, 2015), beneficiando indiretamente mais de cinco milhões de pessoas. Estima-se que o gasto mundial com produtos do CJ já tenha alcançado 5 bilhões de euros, e que na Holanda o café solidário represente $2,5 \%$ do mercado, e a banana $5 \%$. Na Suíça esses números elevam-se a $5 \%$ e $23 \%$, respectivamente. Ainda que, em termos globais, o café equitativo tenha crescido a uma taxa anual média de $16 \%$ até cerca de 2010, e represente aproximadamente $1 \%$ das vendas mundiais, nos últimos anos avalia-se que seu mercado está próximo do saturamento (Jurado, 2015: 139).

Operou-se uma mudança de escala no comércio ético, que deixa de ser um consumo militante para se tornar um consumo massivo. Entretanto, em que pese à grandeza deste novo patamar, o CJ consolidou-se em determinados nichos de mercado marcados por atitudes solidárias a produtos do Sul, como os produtos tropicais e o artesanato. Apesar da recente expansão do CJ, ele absorve apenas $0,02 \%$ do comércio internacional.

\section{DIFERENCIAÇÕES CONCEITUAIS E ORGANIZACIONAIS}

Vale destacar que há graves problemas na literatura sobre o CJ, especialmente a produzida diretamente por suas organizações. Em geral seus atores difundem uma visão romântica, acrítica e otimista sobre o CJ e seus efeitos, ignorando os desafios atuais desta prática comercial, os jogos e estratégias de mercado, custos de produção, indicadores de resultado econômico. Mas, especialmente, pouco se conhece do impacto do CJ Norte-Sul sobre as comunidades locais de produtores; seus efeitos para o desenvolvimento local começam agora a ser investigados. $\mathrm{Na}$ América Latina em particular, praticamente não há balanços que permitam precisar a dimensão efetiva do CJ, ou mesmo a real extensão das redes de economia solidária ${ }^{5}$. Há um prolixo discurso, mas poucos dados socioeconômicos concretos. Mesmo imprecisos, os números relativos

\footnotetext{
${ }^{5}$ A avaliação do CJ na região andina (Bolívia, Colômbia, Equador e Peru) feita por A. Cotera em 2009, apesar de sua amplitude, é um exemplo destes limites. Artisans du Monde (2004) confirma a precariedade dos estudos de impacto do CJ sobre as comunidades feitos até então, e conclui que o CJ fica restrito a produzir melhorias nas condições de vida dos produtores, sem gerar um processo de desenvolvimento local e regional. Trabalhos mais realistas que discutem empiricamente os efeitos do CJ sobre os camponeses na América Latina se encontram em: Fair Trade Research Group da Colorado State University (http://cfat.colostate.edu/wp-content/uploads/2009/09/One-Cup-at-a-Time.pdf); Community Agroecology Network (CAN): http://www.canunite.org/ Food First - http://foodfirst.org/. Destaco: "Fair to the last drop, the corporate challenges to fair trade coffee": http://foodfirst.org/wp-content/uploads/2013/12/DR17-Fair-to-the-Last-Drop.pdf; Relatório de CLAC (Bacon; Flores, 2007); A Plate-Forme Pour le Commerce Equitable - PFCE (aliança formada pelos pioneiros do CJ francês: http://www.commercequitable.org/images/pdf/impact/what $\% 20 \mathrm{do} \% 20 \mathrm{we} \% 20 \mathrm{really} \% 20 \mathrm{know} \% 20$ about $\% 20 \mathrm{ft} \% 20 \mathrm{impacts}$.pdf; Méndez et al., 2010.
} 
ao CJ são expressivos. Porém, eles não traduzem o significado profundo do mesmo e os dilemas hoje postos a ele.

Com frequência faz-se a apologia do fortalecimento da autonomia e da inserção indígena/camponesa nas redes de comercio justo, porém sem investigar empiricamente as mudanças que o fair trade traz para estas comunidades e ao ecossistema regional. Mas, mesmo quando esta literatura tem um grau maior de rigor e criticidade, a ausência destes dimensionamentos faz com que ela não vá além da retórica e da exortação ética ${ }^{6}$. O nobre e bem intencionado esforço do CJ, desprovido de compreensão sobre a materialidade do seu próprio metabolismo e do processo histórico em que se insere, corre o risco de ser absorvido pelo free trade que ele busca corrigir e superar.

O conceito hegemônico de CJ, rigorosamente, reflete intercâmbios globais entre o Sul e o Norte. Na definição consensuada por FINE em dezembro de 2001,

Comércio justo consiste em uma parceria comercial, baseada no diálogo, transparência e respeito, que busca maior equidade no comércio internacional. Sua contribuição ao desenvolvimento sustentável se dá pelo oferecimento de melhores condições de troca e garantias dos direitos a produtores e trabalhadores marginalizados, particularmente no Sul, estando orientado para a solidariedade dos consumidores do Norte com os produtores do Sul (IFAT, 2001).

Aqui a ideia nuclear é reduzir a pobreza do Sul através do acesso aos mercados do Norte por parte dos produtores marginalizados. Apesar desta hegemonia, há mais de uma modalidade de CJ. Isto se constata no forte debate entre seus atores sobre o que vem a ser fair trade, uma vez que nem todas as práticas comerciais fundadas numa ética solidária estão englobadas neste conceito, inclusive muitas tampouco se identificam como de CJ.

Nem todos os empreendimentos que se encontram no CJ são organismos plenamente orientados por relações econômicas justas e solidárias, nem estão envolvidos mais profundamente na cadeia produtiva solidária ou nas redes do movimento da economia solidária. A partir do momento em que FLO admite a participação das grandes corporações, surge a presença no commerce equitable de parceiros comerciais que, com fins lucrativos, se associam ao sistema de CJ especializados exclusivamente na ponta final do ciclo econômico solidário.

Esta abertura leva à diluição dos valores iniciais do fair trade, podendo comprometer o próprio sentido das palavras "comércio justo" e deixá-las irreconhecíveis. Neste sentido, Marco

\footnotetext{
${ }^{6}$ Como é o caso de Johnson (2004a; 2004b), influente consultor das redes de CJ.
} 
Coscione, coordenador da CLAC, defende que se deva lutar, no seio do movimento, pela preservação do significado original do CJ: "construir um mercado solidário para quem nunca teve aceso direto e em condições justas ao mercado, os pequenos produtores organizados, e não as empresas tradicionais" (2015: 12).

Se opondo ao sistema de certificação da FLO, e buscando diferenciar de outras entidades comerciais, a IFAT lançou em 2004 seu próprio selo de CJ, atestando as organizações comprometidas com proteção do meio ambiente, com os direitos humanos e condições de trabalho (salários adequados, combate ao trabalho infantil). O mesmo fez a CLAC em 2006, com seu selo Símbolo de Pequeños Productores (SPP), reafirmando os valores postos na gênese do CJ.

Nesta perspectiva, para diferenciar da forma canônica de CJ, que requer certificação FLO, algumas redes, que operam no mercado de produtos da economia solidária através de feiras e outras formas de intercâmbio comercial, trabalham com categorias que ampliam a conceituação “oficial”. É o caso das expressões Comércio Solidário, Comércio com Justiça, Comercialização Comunitária, Comércio Responsável, ou mesmo Comércio Sadio. Não se trata de irrelevantes sutilezas semânticas, mas de noções que definem um tipo de CJ que geralmente se exerce em mercados que não são de exportação e nos quais não se aplica obrigatoriamente a certificação de fair trade. São práticas comerciais exercidas através de relações respeitosas e mutuamente benéficas entre os produtores e os compradores, seguindo critérios de preços, qualidade, intermediação mínima, transparência nas contas, compromisso de longo prazo. Elas não se identificam tanto pelo tipo de produto, mas pela relação direta que se estabelece entre produtor e consumidor. Ás vezes estas relações não são formalizadas, dificultando a identificação do setor.

O México logrou constituir com sucesso um importante mercado interno de CJ, sendo o primeiro país do Sul a estabelecer, em 2001, um selo próprio de âmbito nacional. A Comercio Justo México (CJM) nasceu em 1999 a partir da iniciativa de organizações de pequenos produtores agrícolas, principalmente cafeicultores, visando promover a venda de produtos no interior do país. Os demais países do Sul praticamente se limitam a exportar seus produtos de melhor qualidade para o Norte.

Uma importante diferença para com o fair trade da FLO, é que o CJM apenas reconhece as organizações de pequenos produtores. O selo mexicano de CJ possibilita diferenciar os produtos dos pequenos produtores mexicanos no mercado de consumo, bem como valoriza mercadorias 
não apreciadas nos países do Norte (mesmo pelo CJ), mas que no México tem forte demanda, até porque são centrais para a subsistência da população. Isto proporciona um desenvolvimento territorial mais integral, pois fortalece os circuitos econômico-solidários ao permiti-los expandir cultivos básicos para a segurança e soberania alimentar, como nopal, tuna, amaranto e as inúmeras espécies de milho crioulo, por exemplo.

Além disto, o estabelecimento de intercâmbios Sul-Sul contribui para quebrar as relações coloniais presentes quando o Sul meramente se adapta a produzir aquilo que agrada apenas aos gostos dos consumidores do Norte, ainda que pautado por padrões éticos. Entretanto, mesmo dentro do México a presença do fair trade ainda é marginal.

Ou seja: a depender do enfoque de CJ utilizado, se com ênfase no "comércio", ou com ênfase no "justo" e no movimento social; se favorável à participação das grandes corporações, ou preservar o CJ para os pequenos produtores, encontramos redes distintas, cada qual com suas próprias categorias, instâncias de coordenação e núcleo duro decisório, e com suas estratégias de comercialização. Apesar das disputas de poder, não há, ainda, uma polaridade rígida e feroz, mas uma polarização dinâmica e pragmática: organizações com concepções distintas interagem e estabelecem parcerias tanto operacionais, quanto políticas, ainda que muitas vezes pontuais, numa confusa competição por nichos de mercado e pela melhor interpretação do que é CJ. Enfim, não se trata de diferenças que geram um irreconciliável antagonismo, mas um sinal de pluralidade e complementaridade, pois todos, ainda que por caminhos diferentes, se reconhecem parte do movimento por um comércio ético e solidário. Pelo menos por enquanto.

\section{A BATALHA DO MÉXICO RURAL}

La batalla por el campo mexicano ha sido larga, cruenta y difícil. Está lejos de haber terminado, y de su desenlace no solo depende el destino de los campesinos mismos, sino el de la nación entera (Gustavo Esteva).

Portanto, foi em torno do café mexicano, produto emblemático do fair trade, que se constituiu o mecanismo do CJ mundialmente dominante. Pela força e especificidades com que o CJ se apresenta neste país, características advindas de seu próprio contexto acabaram moldando a 
forma como o fair trade amplamente é reconhecido. ${ }^{7}$ Para além do seu pioneirismo, o México é a nação do Sul onde o comércio ético está mais avançado. Isto não surge por acaso.

500 anos de história de infinita violência rural fizeram dos camponeses protagonistas chave da construção nacional do México. Em 1910, 100 anos após terem feito possível a independência, camponeses pobres derrubam a ditadura de Porfírio Díaz e fazem a primeira revolução social do século XX. "Tierra y libertad". Com este lema fortemente anarquista, Emiliano Zapata aglutinou seu exército revolucionário que liquidou o porfiriato e plasmou o moderno Estado mexicano. Mas, a hegemonia militar de Zapata e Villa não se traduziu em poder político, e os camponeses tiveram de aguardar a reforma agrária do governo de Lázaro Cárdenas (1934-1940) para que a revolução camponesa se pusesse em marcha novamente.

A permanente presença no meio rural de organizações comunitárias em grande parte se explica pela proteção jurídica dos ejidos advinda da Constituição de 1917; e pelos limites legais a que o capital tivesse acesso direto à agricultura, pois estava proibido que empresas mercantis explorassem a terra. As reformas agrárias ao longo do séc. XX e os processos de resistência e de organização social geraram uma progressiva recuperação da posse da terra pelas populações indígenas e camponesas, levando a reconhecer a propriedade coletiva em 103 milhões de hectares pertencentes a 30.000 ejidos com 3,1 milhões de famílias. Assim, índios e “índios desindianizados" possuem mais da metade do território nacional.

Ou seja, a comunidade rural, ao invés de dissolver-se como classicamente ocorre com o avanço do capitalismo, permaneceu como opção concreta com potencial para alavancar alternativas de desenvolvimento que porventura apresentarem-se no processo histórico. Isto se expressa economicamente na forma de potente circuito de economia popular presente em tendas e feiras nas ruas das cidades mexicanas, especialmente no DF, em geral de alimentação, na maior parte das vezes preparada com variedades nativas e crioulas. A existência contemporânea duma agricultura e silvicultura de base indígena produtora de destacados artigos básicos para o sustento da população é uma conquista de um México profundo e persistente (Bonfil, 1990).

Entretanto, se "o movimento agrarista conseguia destruir ou desarticular as antigas unidades produtivas, vinculadas à fazenda porfiriana, poucas vezes lograva construir outras que

\footnotetext{
7 "In a sense, the "mistake" made by founders of Fair Trade and of the movement that they helped to establish was to believe that what applied to the Latin American context could also work in other developing regions. If FT had been born in the African context, it would probably have had a greater focus on mining or petroleum products. Likewise, if it had been inspired in Asia, it would probably have been more specialised in the trade of textile products and clothing" (Sylla, 2014).
} 
as substituíssem através da organização coletiva camponesa” (Esteva, 1980: 46). Nesta situação, o domínio absoluto ao longo de décadas do Partido Revolucionário Institucional (PRI), presente amplamente nas organizações estatais que regulavam fortemente todos os grupos sociais, cobrou alto preço, passando a sujeitar os camponeses promovendo organizações implantadas desde cima e externas à própria vida dos mesmos.

Progressivamente, passa a ter decisivo papel na estrutura de poder local e regional o Cacique, operando como intermediário entre os camponeses e as autoridades nacionais, levando as contradições sociais mexicanas a um callejón sin salida. A partir dos anos 1970, buscando saídas para a "ditadura perfeita" do PRI, recobram força organizações camponesas e indígenas independentes do Estado, o que, face às contradições e à estrutura coronelística de poder dominante, incrementa a violência no campo.

Varridos por ventos neoliberais, os anos 80 foram de forte crise econômica para o México. Somado a queda brutal dos preços mundiais, decorrente da ruptura dos acordos da Organização Internacional do Café, que colapsa com a pressão desregulamentadora, os produtores de café, abandonados à sua própria sorte, partiram em busca de alternativas e organizações independentes. Porém, muitos migraram ...

"Pobre México, tão longe de Deus, tão perto dos Estados Unidos". Ainda que os problemas no relacionamento com os EUA sejam antigos, a avalanche migratória se agrava com a entrada em vigor em 1994 do Tratado de Livre Comércio da América do Norte (NAFTA), e com a maior queda de preços da história do café. O NAFTA levou a comprometer parte substancial do mercado interno de grãos básicos, afetando a soberania alimentar mexicana. De autossuficiente e exportador de alimentos básicos, o México passou a importar 40\% dos grãos e oleaginosas que consome. A população que permaneceu no campo, se já era pobre, ficou ainda mais miserável. As políticas neoliberais trouxeram a ruína do México rural.

3.1 O sistema camponês-indígena de produção de café

Desde siempre el café fluye de la periferia al centro, del calor al frío, del subdesarrollo a las metrópolis (Armando Bartra). 
Além de ter sido o primeiro produto do CJ, o café tem sido sua principal mercadoria. É um produto que simboliza todos os dramas e a injustiça do comércio internacional, pois é produzido por uma multidão de trabalhadores no Sul, e seus preços são fixados por uns poucos compradores no Norte, para onde a maior parte da sua produção é exportada. O preço duma taça de café numa nobre cafeteria equivale ao ganho diário de um agricultor. Cinco empresas transnacionais compram metade dos grãos de café consumidos no mundo e controlam sua cadeia de valor, enquanto que 25 milhões de famílias de pequenos produtores no Sul padecem as consequências destas relações comerciais (E. Vivas). Em nível mundial, o café representa a segunda matériaprima (legal) em importância nos mercados internacionais, só superado pelo petróleo, ocupando o primeiro lugar entre os produtos agrícolas de exportação.

México, quinto produtor mundial de café, pratica um cultivo mini fundista em geral sob sombra e acompanhado de outras espécies (normalmente destinadas para o autoconsumo), com 280 mil produtores, dos quais $92 \%$ tem menos de 5 hectares, sendo $65 \%$ destes pequenos cafeicultores membros de grupos indígenas.

Os baixos custos de produção no Brasil e Vietnam tornam difícil aos cafeicultores do México competir no mercado a não ser com algum grau de diferenciação. É a qualidade que determina o segmento de mercado no qual participará. Isto é: um café de baixa qualidade permanecerá no segmento de baixos preços, mesmo tendo uma distinção de origem, social ou ambiental, enquanto que um de alta qualidade obterá melhores preços.

A produção de café se concentra nas zonas mais pobres do sul do México, representando uma das poucas oportunidades de obter uma renda monetária para a população rural destas regiões. Após sobreviver às inúmeras políticas anticamponesas do Estado mexicano e às profundas e devastadoras crises da economia cafetaleira, as famílias de pequenos produtores de café hoje mostram que seu sistema de produção é viável e configura uma resposta social criativa e independente. Isto leva Josefina Aranda (2004) a afirmar que o café mexicano é um autêntico sistema campesino-indígena de produção, pois: i) Grande parte da área cultivada com café no México corresponde a produtores indígenas que trabalham com menos de cinco hectares; ii) A produção de café ocorre no contexto de uma economia doméstica camponesa; iii) A produção de café se dá basicamente em comunidades e regiões que possuem severas carências na dotação e funcionamento de todo tipo de serviços e infraestrutura básica; iv) Os produtores de café possuem um forte espírito comunitário para o trabalho e para a organização. 
Enfrentando o cenário desolador formado pelas políticas neoliberais nos anos 80/90, os agrupamentos cafeicultores passam de simples representações clientelares unidas ao Estado e ao PRI e fortemente explorados por coiotes, para construírem organizações independentes e uma estratégia produtiva autogestionária. Os cafeicultores são o ator do setor social mais organizado do país. A partir de 1988, para controlar o processo de produção e comercialização e solucionar seus problemas, várias organizações regionais de pequenos cafeicultores fundaram a Coordinadora Nacional de Organizaciones Cafetaleras (CNOC), uma rede nacional autônoma formada por 125 organizações que agrupam 75 mil pequenos produtores de café.

Até 2006 o México era o principal produtor de café (e mel) orgânico - e com selo de garantia de CJ - no mundo, tendo sido superado pelo Peru que vem ampliando rapidamente sua produção. $10 \%$ das plantações de café do país e 33\% da superfície cultivada mexicana são com métodos orgânicos. 2/3 do seu cultivo ocorre em regiões com selvas e bosques, havendo nas regiões cafeicultoras uma grande diversidade de fauna e flora.

Operando com eficiência no nicho do circuito da agricultura orgânica e do CJ, diferenciam sua produção, agregando aquilo que os camponeses mexicanos têm maior vantagem comparativa, que são os valores sociais e ambientais, dando visibilidade internacional para a cafeicultura mexicana. Chiapas e Oaxaca, não por acaso os estados com maior concentração de população índia, maior diversidade biológica e maiores níveis de pobreza do México, detinham em 2005, de acordo com Certimex, $58 \%$ e $31 \%$ da área orgânica cultivada com café, totalizando mais de 70 mil hectares distribuídos entre 34 mil produtores.

O desaparecimento da Organização Internacional do Café gerou imensas flutuações nos preços e grandes tormentas no mercado mundial de café. Com os preços extremamente baixos, o CJ, ao assegurar um preço mínimo e um nicho estável de mercado, não apenas impediu um empobrecimento ainda maior dos pequenos produtores, como também garantiu um "salário mínimo" ou um "seguro" aos mesmos, lhes propiciando uma relativa estabilidade econômicosocial. Podendo contar com um preço fixo pela colheita, e até mesmo com pagamento antecipado de parte da produção (crédito), os cultivadores de café registrados no CJ planificam melhor suas necessidades familiares, enquanto quem está no mercado convencional tem de esperar pela venda de seu café para saber quanto irá obter.

A princípio, a estratégia mexicana de CJ é bem-sucedida comercialmente, especialmente na construção de um importante mercado interno de CJ. Não há dúvida de que o café mexicano de 
CJ é um exemplo paradigmático do processo de construção social dos mercados, confirmando o papel protagônico dos consumidores e produtores organizados, e desmentindo as teorias econômicas que afirmam serem estes indivíduos atomizados que apenas maximizam seu bemestar no mercado (Gonzáles, 2005: 106). O fair trade possibilita retirar a comercialização e transformação do café das mãos dos grandes produtores e transformar o frágil campesinato em um importante ator do jogo econômico. O comércio equitativo beneficia as populações indígenas, fortalecendo sua autoestima, identidade, impulsionando uma maior equidade de gênero, e gerando dinâmicas de desenvolvimento endógeno.

O amplo, e raro, estudo de impacto do sistema de café de CJ na AL e Caribe promovido pela CLAC (Bacon; Flores, 2007), mesmo reconhecendo que os resultados comunitários foram medidos em menor escala que os outros dois níveis de impactos, informa sobre diversas conquistas sociais lá ocorridas. Todavia, reconhece que "los ingresos siguen siendo insuficientes, desiguales e injustos" (ibid., viii; grifo nosso). Apenas de 20 à $25 \%$ do café produzido pelos produtores certificados é vendido nas redes de CJ (Bacon; Flores, 2007: 6). O retorno obtido nas redes alternativas é insuficiente para cobrir todos os custos da produção ecológico-solidária. Assim, os cafeicultores permanecem vinculados ao mercado convencional, pois tanto nele vendem o restante da produção, quanto com ele negociam quando os preços dele forem atrativos, enfraquecendo suas cooperativas e debilitando-os se os preços voltarem a cair. Efetivamente, se os preços do fair trade deixarem de ser atrativos por um longo período, os produtores repensarão seu vínculo com o mesmo.

Em períodos de preços altos, como ocorrido entre 2010-2011 e 2011-2012, muitos cafeicultores rompem com sua cooperativa, pois obtém rendas maiores no mercado convencional. A redução de tudo a preços dissolve todo trabalho político, demonstrando que, para os produtores, CJ significa “el acceso a um mejor precio, sin más trascendencia” (Jurado, 2015: 94).

Em contrapartida, se levarmos em conta o preço pago pelos intermediários locais nas épocas de crise do café, os sócios das cooperativas obtêm o dobro e até o triplo do mesmo. Quando os preços flutuantes do mercado internacional estavam baixos, o cultivo certificado (orgânico e social) recebeu em média 1/3 acima, evitando a perda nas épocas mais difíceis de aproximadamente 750 dólares anuais por família (considerando uma produção média familiar de café de 1.000 libras, e que $25 \%$ dela é vendida no CJ). 
Em verdade, a comparação com o café convencional é indevida pois os custos da produção alternativa também são maiores. Além disto, como o café certificado compete no mercado de café de café de alta qualidade, cujo preço internacional é mais elevado, a diferença de preço é mínima, pulverizando o prêmio (valor pago acima do preço mínimo certificado) social e ambiental que a organização recebe do CJ.

Ao contrário dos que afirmam que o fair trade reduz a imigração, estudos na América Central e México mostram que os membros das cooperativas de CJ mais prósperas na realidade imigravam mais que as demais pessoas da comunidade. O irônico está em que a imigração se faz possível porque os ingressos relativamente superiores que agora obtinham lhes permitiam pagar as caras comissões dos coiotes para cruzar a fronteira estadunidense (Bacon; Flores, 2007: 19).

Portanto, é bom ter cautela antes de proclamar os resultados, pois o sistema camponêsindígena de café não existe em estado de pureza, mas coexiste entranhadamente com o dominante; e seus participantes, mesmo quando integrados ao fair trade, continuam lutando pela sobrevivência e contra a pobreza. Efetivamente, é saudável que as cooperativas de produtores diversifiquem suas opções comerciais evitando depender de alguma em particular (inclusive do CJ) e de modo a saber se posicionar nos diferentes mercados.

Cabe ter cuidado com afirmações generalizadas e conclusivas tanto sobre os impactos do CJ (pois seus efeitos práticos sobre as populações produtoras variam conforme a visão e as estratégias adotadas por cada organização de base, as quais são muito diversas); quanto a respeito de quanto ganham os campesinos, pois estamos falando populações em situações muito difíceis. Hoff já esclareceu que com o café as famílias aumentaram sua renda de um dólar por dia, para dois dólares... Os estudos de impacto revelam que os produtores de CJ tem rendas apenas um pouco maiores que os convencionais, não sendo suficiente para mudar completamente sua situação. Porém, o fato destas rendas terem maior estabilidade e estarem menos sujeitas a grandes flutuações, lhes dá maior segurança e possibilidades de permanecerem como camponeses, além de também desencadearem outros benefícios políticos e sociais, gerando dignidade e reconhecimento em populações secularmente oprimidas e inferiorizadas.

Para Bartra (2003: 83) esta conversão produtiva para um “café social e sustentável” de regiões cafeicultoras empreendida por um conjunto de pequenos e médios produtores organizados é uma "grande transformação agrária". Mas, o sucesso comercial, político e cultural resume-se a ser uma fonte de renda regular e dar estabilidade para o pequeno produtor rural, propiciando-lhe 
uma segurança frente à queda de preços e reduzindo sua histórica vulnerabilidade. Isto não é pouco.

\subsection{Descolamento entre as redes indígenas econômicas e políticas}

Observa-se um fortalecimento da organização indígena e suas demandas por autonomia na América Latina como um todo, especialmente no México contemporâneo, fenômeno que se agudizou com o levante do Ejercito Zapatista de Liberación Nacional (EZLN) a partir de 1994. Que relações isto teria com o crescente fortalecimento econômico das redes camponesas de CJ no mesmo território? Até que ponto o empoderamento econômico indígena não refletiria e transbordaria para o plano político autonômico? Para além da coincidência espaço-temporalétnica, ambas redes lutam simultaneamente por uma outra globalização, questionando profundamente o projeto neoliberal encarnado pelo NAFTA e o sistema político-econômico mexicano.

Porém, o relacionamento destes vizinhos não vai bem. Fato revelador das dificuldades ocorreu em 2007, quando entidades da sociedade civil mexicana convocaram um boicote dos “Cafés La Selva”. Um de seus sócios, a Unión de Ejidos de la Selva, uma exitosa organização econômica indígena chiapateca, desalojou violentamente 31 famílias de uma comunidade zapatista que nela viviam como refugiados da guerra civil mexicana. A UES foi então acusada de ser uma organização paramilitar.

Infelizmente, a literatura que discute a organização política indígena é omissa sobre as implicações da óbvia coexistência destas redes. Tanto os trabalhos de Lópes Bárcenas, quanto de Días-Polanco, por exemplo, descrevem muito bem (antropológica, política e juridicamente) o fortalecimento da comunidade indígena no México contemporâneo, inclusive demonstrando que, nestes tempos de autonomia, a comunidade indígena está se transformando aceleradamente. Porém, não discutem a inserção das mesmas nas redes de CJ e os impactos do fair trade sobre as comunidades.

Em parte, há aqui uma atitude de precaução e cautela, pois, dada a conflitiva situação posta na região com o levante do exército zapatista, estes pesquisadores procuram preservar e ocultar os possíveis laços que existam entre estas organizações, de modo a protege-las da repressão do Estado mexicano. Todavia, em verdade, esta literatura reflete também um descolamento real entre 
as organizações políticas de base índia e suas similares redes econômicas. Esta dissociação decorre tanto dum esquerdismo que deprecia a importância da auto-organização econômica comunal, quanto das direções das organizações de CJ atentas apenas às "n" demandas de natureza comercial. $^{8}$

Apesar da sustentação econômica e das relações materiais de reprodução das comunidades indígenas ser uma dimensão estratégica para a construção do poder local e da autonomia comunal, inexiste sintonia entre a afirmação radical da autonomia das comunidades e seu caráter alternativo, e a perspectiva do fortalecimento de uma economia não capitalista.

Alguns argutos observadores da cena zapatista alertam para a necessidade de que a condição para o êxito político do movimento zapatista e das demandas autonômicas depende de estar alavancado em alternativas econômicas em suas regiões". Toledo chama de "outro zapatismo" ou "zapatismo silencioso" estas experiências comunitárias e de cooperativas de autogestão e empoderamento social fundadas no controle dos territórios, na produção ecológica e orientadas pelos princípios do “desenvolvimento sustentável”. Contudo, as posições de Toledo e semelhantes tem sido fortemente rejeitadas pela liderança do EZLN.

O fortalecimento comunal não está fora do espaço mercantil. Uma comunidade que não tenha controle sobre suas cadeias de comercialização é débil. Porém, nenhuma comunidade tem o controle absoluto de todas suas variáveis, pois não há comunidade que seja totalmente autárquica. Ainda que ambas estejam arraigadas na cultura e na vida cotidiana, a autogestão econômica e a autogestão política possuem seus próprios ritmos e demandas, as quais nem sempre confluem. Diante deste quadro, é razoável e realista esperar lograr "construir o poder popular" desde baixo e desde dentro, apenas, como proclamam os zapatistas? O imperativo do mercado exige profissionalismo e gestão eficaz, o que nem sempre é compatível com as instâncias coletivas de decisão.

Isto explica a divisão de águas crescente entre duas redes de organizações indígenas no mesmo território, a econômica (cafetaleira) e a política (tanto a zapatista, em Chiapas; quanto a Asamblea Popular de los Pueblos de Oaxaca - APPO, em Oaxaca). Se o emergente fenômeno da organização econômica comunitária não se articula e se envolve com as lutas de resistência e a

\footnotetext{
${ }^{8}$ A pesar desta apartação organizacional-política, a coexistência espacio-temporal com a luta autonomista indígena gera graves problemas para as cooperativas. Em 1994 os militares ocuparam a escola de agricultura de UCIRI em Oaxaca, acusando-a de ser um centro de adestramento paramilitar do EZLN, agredindo violentamente seus membros (Waridel, 2004: 49).

${ }^{9}$ Mestries (2006) e Toledo (1999; 2001), por exemplo.
} 
ação cidadã, arrisca-se que os inevitáveis câmbios ao interior da comunidade derivados do "enriquecimento" material proveniente de CJ aprofundem diferenciações na mesma (castrando a possibilidade de um verdadeiro desenvolvimento comunal), bem como as cooperativas de CJ sejam absorvidas pelo especulativo mercado global. Se ele se envolver, arrisca não gerar o almejado "enriquecimento".

Constata-se ainda uma dissociação crescente das redes e organizações de CJ, com o movimento de economia solidária e as organizações indígenas e camponesas que lhe deram origem. Ao contrário, muitas das organizações camponesas/indígenas estão a comercializar com Wal Mart, Carrefour, Sanborns, Starbocks... Fortes redes de economia camponesa e indígena mexicanas participam do CJ. Porém, elas não pertencem, em geral, às redes de economia social e solidária de México. A questão é que este outro mercado modelado pelo fair trade progressivamente se afasta e deixa de se identificar e se incorporar às redes que militam por uma outra economia, solidária. Como o movimento da ecosol se caracteriza por buscar um enfoque integral do processo econômico, incorporando, por exemplo, dimensões de territorialidade e soberania alimentar, isto pode significar que o CJ está se limitando a uma visão reducionista da comercialização.

Devido a grande maioria dos produtores estar na dura luta pela subsistência, o mais provável é que, em parte, este divórcio advenha das cúpulas organizativas que representam e controlam todo o sistema, as quais se mantêm absortas no gerenciamento comercial do mesmo. Porém, como efetivamente há uma intrínseca participação democrática dentro do sistema indígena de produção, e como ele é gerenciado por suas próprias lideranças, não se pode descartar a hipótese deste distanciamento refletir algo mais profundo.

Os estudos disponíveis dos efeitos do retorno financeiro do CJ sobre as comunidades camponesas em geral valorizam positivamente os mesmos. Porém não são conclusivos (a miríade de experiências também dificulta qualquer generalização), e não conhecemos todas as mudanças ocorridas ao interior das mesmas, não sabemos que diferenciações podem estar a se ampliar. Infelizmente, há poucos e qualificados estudos de impacto do CJ sobre as comunidades produtoras. A questão não é apenas avaliar o "impacto" através de contas financeiras. Há uma grande lacuna de dados, tanto quantitativos, quanto qualitativos.

Há transformações que para captá-las bem exige inserir-se totalmente nas comunidades e falar as línguas indígenas. Ou seja, não basta uma análise econômica ou sociológica para revelar 
o que de mais profundo está se passando. Fazem falta aqui estudos de corte geográficos que aufiram as novas rugosidades espaciais imprimidas pelos novos fluxos comerciais, bem como estudos antropológicos.

Os êxitos do fair trade se devem tanto aos esforços dos agricultores para organizar-se localmente, como à certificação. Há uma sinergia entre o amplo trabalho político e social efetuado pelos movimentos camponeses e os ganhos econômicos do CJ. Todavia, apesar de ser advindo das lutas dos indígenas e dos camponeses pela sobrevivência, o estado das artes hoje do CJ registra inúmeros e graves problemas entre as redes de economia solidária, de organização política de base étnica e de CJ indígena: desarticulação, dispersão e divisão interna; progressivo distanciamento e perda de coerência do CJ com os princípios ético-solidários que lhe deram origem; e carência de uma estratégia político-econômica comum e clara, de curto, médio e longo prazo. Este problemático quadro é agravado pelas promessas incumpridas do fair trade.

\section{TENSÕES E DILEMAS}

Muitas são as objeções ao fair trade, como caricaturalizá-lo de "consumismo de solidariedade"; de fair-washing (pois permite as grandes corporações limpar suas imagens); acusá-lo de gerar "desculturalização da produção"; de "nos desviar do essencial" (re-localizar a economia); de ser uma espécie de "comercio para ricos"; ser uma "forma de neocolonialismo" e "um triunfo da globalização neoliberal, além de nos condenar à globalização".

Forte divisor de águas no âmago do movimento do CJ é quanto a participar no grande mercado através de um selo de certificação de origem. Os que defendem esta participação pragmaticamente entendem que, no contexto duma economia globalizada, não se deve desperdiçar oportunidades econômicas postas neste cenário. Para a maior parte das organizações do CJ, um certo realismo aos poucos se impõe, pois, vivemos numa sociedade de marcas. Nela, é imprescindível a necessidade de uma etiqueta de fair trade na qual os consumidores possam confiar.

Argumentos favoráveis à grande distribuição dos produtos da economia solidária nas grandes organizações do comércio convencional são:

i) atingir consumidores que desconhecem o CJ e que dificilmente deslocar-se-iam a uma loja de CJ; ii) viabilizar a produção alternativa. A maioria dos produtores tem uma capacidade de 
produção muito superior àquela que vende ao $\mathrm{CJ}$, e de fato vendem uma parte significativa da mesma no mercado convencional. A ampliação dos mercados proporciona volume de comercialização e permite atingir a escala necessária para consolidar este outro paradigma produtivo; iii) o CJ é muito mais do que vender produtos. Sua missão é mudar as regras do comércio internacional, e isto se alcança quando suas redes tiverem peso significativo no mesmo.

Os contrários à certificação argumentam que para os maiores compradores de café, o fair trade constitui uma pequena parte de suas compras de café - menos de dois por cento. Para estas empresas, avaliam, o CJ não é um movimento social ou um comércio ético, mas uma oportunidade de melhorar sua imagem pública e um nicho rentável. Se aproveitam do "efeito halo" - a confiança em um único produto repercute sobre toda a marca.

Censuram que as certificadoras apenas estão tomando o lugar dos pequenos intermediários locais, substituindo-os. "O 0,06 de euro que os "coiotes" (intermediários) recebiam no preço de um pacote de café foi substituído pelo 0,05 euro exigido pela Max Havelaar" (Jacquiau). Os críticos denunciam que o CJ foi tragado pela onda neoliberal, transformando-se em comércio do justo. O próprio co-fundador da Max Havelaar, Frans van der Hoff, lamenta que, de um movimento anticapitalista, a dimensão política do CJ "foi aos poucos edulcorada e apagada".

Denunciam ainda que a ênfase do CJ em commodities de exportação prejudica os cultivos domésticos e a soberania alimentar das populações locais.

Os que se opõem à certificação FLO acentuam que apenas grandes organizações conseguem obtê-lo, havendo pequenos produtores de ecosol que de fato são justos, porém não podem aceder ao selo, pois não podem pagar para obtê-lo, pois são exatamente os mais pobres. Provavelmente este modelo de CJ não é adequado para solucionar o drama dos países mais pobres.

Outro forte tensionamento no debate sobre o fair trade é sobre seus limites para enfrentar os graves problemas ambientais contemporâneos. Muitos criticam o CJ por, ao fomentar os circuitos comerciais, não levar em conta os custos ecológicos e favorecer o empobrecimento da biodiversidade. Ora, nem todos os efeitos negativos das trocas internacionais, especialmente os que incidem sobre o meio ambiente, podem ser superados pelo CJ, pois do ponto de vista ambiental cabe buscar o "justo comércio", mais que ampliar o comércio, mesmo que justo.

Nesta perspectiva, um comércio verdadeiramente ecológico deveria incrementar circuitos mais curtos de comercialização (“de proximidade”) propícios ao desenvolvimento de novos 
espaços de solidariedade. A essência do argumento ecológico é de natureza anticomercial, pois, avalia que, por "pisar no acelerador" (o crescimento econômico contínuo, mesmo camuflado de "economia verde, é insustentável”), a economia mundial é "um pacto de suicídio global" - nas

palavras de Ban Ki-moon, Secretário-Geral da ONU. Assim, face uma crise de excesso (obesidade e engarrafamentos de transito crescentes), cabe reduzir o comércio ao mínimo, proclamando as virtudes energéticas da máxima autossuficiência possível. Todavia, apesar de vibrarem teoricamente em frequências diferentes, na prática observa-se um entrelaçamento do CJ com os mercados orgânicos, resultando numa espécie de "consumismo verde".

O produto símbolo do CJ e orgânico, o café de sombra, é considerado como um "café amigável com as aves" (Anta Fonseca, 2006: 7), se diferenciando em muito da monocultura de café produzida em grandes propriedades e sob o sol que necessita de agroquímicos. Entretanto, Silva Rivera (2006), pesquisando sobre os efeitos da produção de café alternativo (tanto o orgânico quanto o de CJ) por organizações indígenas em Chiapas (México) em áreas ainda cobertas por uma floresta primária, aponta que, motivados pelas rendas geradas, vem ocorrendo a substituição dos bosques e da agricultura de subsistência por um ou dois cultivos, havendo uma forte tendência de expandir as áreas de cultivo de café.

\section{DESCOLONIZAÇÃO?}

Efetivamente, "sucesso" comporta riscos, e, muitas vezes, pesados ônus. Como todo comércio de grande escala internacional, o CJ também imprime novas relações e transforma os territórios onde opera. Sendo uma das formas pelas quais os grupos indígenas ingressam na globalização (outras são a migração e/ou o assalariamento, e mesmo como arrendatários), é importante conhecer a repercussão do CJ sobre os mesmos. A inserção nas redes globais de commercio equo e solidale, uma das faces do atual movimento indígena latino-americano, é parte duma reorganização comunal dos povos indígenas, de suas instituições de autogoverno e formas de trabalho e produção. Este fenômeno tem dimensões continentais, com mais relevância na Bolívia, Equador, Guatemala, México e Peru, devido a maior presença indígena nestes países.

A ascensão indígena e camponesa, e dos movimentos negro, das mulheres, juventude e ambientalista, configura uma virada decolonial, rompendo com a colonialidade do poder ainda imanada em nossas sociedades. O surgimento dos Estados pós-coloniais (seja na AL há 200 anos, ou mais recentemente na África), não fez emergir também sociedades descolonizadas nestes 
novos países. Ou seja: aqui o Estado nacional permaneceu, estruturalmente, reproduzindo lógicas de poder colonial que subalternam e discriminam populações por sua condição racial e de gênero. Daí que podemos até nos industrializarmos, porém, aprofundando aberrantes desigualdades e contradições.

Isto hoje está a mudar radicalmente, pois o movimento indígena, alicerçado em dinâmicas comunais de poder que transcendem as instituições estatais, e até contra elas, obteve a proclamação de Constituições (Bolívia, Equador) que reconhecem, pela primeira vez na história, Estados-plurinacionais. A emergência da economia solidária reflete esta auto-organização indígena, desafia o padrão colonial de poder vigente na $\mathrm{AL}$, pois retira da invisibilidade populações classificadas como inferiores, excluídas socialmente. Os que estão no polo de miséria do capitalismo reconquistam, pela organização comunitária de seu trabalho, o acesso a bens e serviços, num autêntico processo de emancipação e democratização, redefinindo e ampliando, com suas cores, línguas e tecnologias, a sociedade vigente e seu modelo de Estado nação hegemônico.

Os novos circuitos econômicos do fair trade espacialmente significam que agora há regiões especializadas no CJ. Isto traz novas configurações territoriais, alterando parcialmente a hierarquia entre os espaços centrais que mandam, e os periféricos que obedecem, pois conecta de modo mais equilibrado o campo com a cidade, o Norte com o Sul, intensificando atividades econômicas que trazem uma maior distribuição do valor gerado. Neste sentido, navegando em direção oposta às tendências mundiais imperantes, o fair trade é uma relativa dissonância no comércio mundial. Enfrentando poderosíssimos cartéis que controlam a indústria alimentar, representa um contra fluxo que permite o desenvolvimento de povos e territórios antes esquecidos (como Chiapas e Oaxaca, as regiões mais pobres e de maior presença indígena no México; ou, semelhantemente, como o Chimborazo, no Equador), alavancando o desprendimento decolonial (Mignolo) e uma nova forma de relacionar o moderno com o não moderno.

Mas, os resultados do CJ não são tão românticos e maravilhosos como aparentam. Ainda que se trate de produção em condições de reciprocidade, produz-se mercadorias voltadas para um mercado globalizado. Aventurar-se nas turbulentas águas do mercado global não é algo que se passa impune. Estamos diante duma armadilha criada pelo capitalismo global, pois, se sem o mercado ninguém pode sobreviver, com ele uma crescente maioria também não pode viver (Quijano). 
Através do comércio alternativo, o mercado global exerce fortes e especulativas influências sobre a economia local de maneiras diversas e inesperadas. Em algumas comunidades envolvidas com o CJ, os indígenas priorizam a produção para exportação, prejudicando seus cultivos básicos. Isto ocorre em consequência do sucesso do CJ, e não de políticas que obstaculizam aos camponeses seguir cultivando seus produtos ... O CJ brotou das lutas históricas pela reforma agrária e pelos direitos dos indígenas e camponeses. Hoje, entre as redes de economia solidária, de organização política de base étnica e de CJ indígena encontramos desarticulação, divisões e progressivo distanciamento.

Porém, ao Sul ainda cabe o fornecimento de produtos primários (commodities), com o Norte controlando os termos de troca, pois são organismos destes países que detém o poder de decisão na FLO, a ponto de Hoff denunciar a existência de uma "estrutura colonial no comércio justo" e propor "decolonizar as estruturas do CJ para reconfigurá-lo a favor dos pequenos produtores" (apud. Jurado, 2015: 84; 116) ${ }^{10}$. Esta situação decorre do conceito de fair trade em vigor fundado nas relações Norte-Sul: voltado para a solidariedade do Norte para com o Sul (o que ecoa ainda algum paternalismo), ele foi acordado no Norte (com a égide da FINE), sob a hegemonia de suas organizações e conforme o interesse de seu mercado.

Infelizmente, o problema não se reduz apenas à tomada de decisão no âmbito da FLO. O ponto crucial é que o CJ está a reforçar os papéis tradicionais da divisão internacional do trabalho e sua matriz colonial de poder, gravitando em torno da produção de mercadorias produzidas intensivamente (monocultura) destinadas ao mercado dos mais ricos, aspecto fulcral do sistema capitalista moderno.

Carraro, Verdú e Fernándes (2005: 114) acrescentam ainda que, como mais $70 \%$ dos produtos de alimentação (principal categoria de venda) do CJ culminam seu processo produtivo nos países do Norte, esta agregação de valor beneficia o circuito econômico do Norte, mantendo a tradicional estrutura colonial de intercâmbio comercial Norte-Sul que desvaloriza os produtos primários e sobrevaloriza os de maior composição tecnológica. Nestas circunstâncias, um preço justo um pouco melhor que o das bolsas mundiais apenas é um paliativo, e não uma transformação desta situação.

Em que pese ofertarem um amplo leque de produtos agrícolas, poucos produtos, em geral, de sua pauta de produção fogem deste estereótipo (praticamente apenas artesanato e têxteis). O

\footnotetext{
${ }^{10} \mathrm{Em} 2013$ se conquistou uma mudança estatutária que possibilitou as três redes continentais de produtores (AFN, NAPP, CLAC) deter $50 \%$ dos votos da Assembleia Geral de FI.
} 
CJ reafirma, assim, a colonial divisão internacional do trabalho, onde os países empobrecidos estão confinados apenas ao fornecimento de matérias primas e produtos primários, enquanto os mais ricos avançam para a terceira revolução industrial, exploram o espaço, o fundo dos mares, o átomo e a nanotecnologia, produzem computadores e todos os dispositivos comunicacionais ... Se não superar este marco e continuar fixado nesta ruralização de seu portfólio, o CJ se reduzirá a ser uma estratégia recolonizadora, traindo sua promessa transformadora.

Todavia, provavelmente sem o CJ muitas comunidades estariam ainda mais desarticuladas, pois elas ficariam completamente à mercê dos efeitos disruptivos do mercado neoliberal. Porém, esta é uma hipótese heurística que, se elucida a importância dos esforços para mudar as regras do jogo comercial (colocando vantagens e possibilidades para aqueles que, operando em cadeias econômicas oligopolizadas, tradicionalmente não tem opções), não minimiza as sérias dificuldades presentes.

\section{CONCLUSÕES}

La producción orgánica de café y el mercado justo son, por ahora, excepciones; nichos de tecnología sustentable y economía moral que confirman la depredadora inmoralidad del resto. Ojalá sean, también, paradigmas de una utopía posible (Armando Bartra).

Ultrapassada sua fase juvenil após três décadas de CJ certificado, alcançou-se tal tamanho e complexidade, com uma emaranhada estrutura burocrática, que ele se transformou a ponto de alguns já buscarem "tornar justo o comercio justo". O entusiasmo inicial esfriou e passou, e agora

vivemos o desencanto com as suas grandiosas e revolucionarias expectativas iniciais. O que sobrou? Que lições tirar?

Não há dúvida de que o CJ se consolidou e vem beneficiando substancialmente setores que outrora estavam marginalizados e empobrecidos, pelo menos aqueles que logram alcançar os padrões exigidos para nele operar. Tampouco se dúvida de que ele seja uma ferramenta útil para o desenvolvimento local, especialmente de regiões periféricas e economicamente debilitadas. Todavia, ainda que sejam inúmeros os seus aspectos positivos, e que não se possa desqualificar sua importância, tampouco pode-se ignorar os graves limites que perpassam o CJ (e também a ecosol). 
Pretender que o CJ gere uma modificação substancial do comércio mundial de modo a obter uma maior equidade no mesmo é um objetivo um tanto quanto pretencioso. Problemas globais exigem soluções também globais, e não apenas locais, ainda que a contribuição destas seja relevante e não desprezível.

Esta limitação decorre, entre outros fatores, do fato do experimento de CJ não poder ser generalizável, pelo menos em curto e médio prazo, ao conjunto das mercadorias atualmente demandadas na vida moderna. Presentemente ele é eficaz apenas em nichos postos nas frestas da globalização e que se viabilizam por capacidades organizativas e qualidades humanas que não são facilmente replicáveis.

Além desta limitação, há uma outra, ainda mais grave, de natureza ideológica: a visão da auto-organização comunal como condição suficiente para superarmos o capitalismo. A centralidade do CJ nos aspectos comunitários e éticos-individuais tem uma boa dose de ingenuidade, pois partilha da crença na ilusão de que toda sociedade pode se autorregular harmoniosamente, sem conflitos e antagonismos irreconciliáveis, o que somente seria possível, talvez, se todas pessoas fossem absolutamente homogêneas. Ora, inclusive entre irmãos, como demonstra o mito de Abel e Caim, irrompe rivalidades fraticidas.

As disputas políticas ao interior da FLO confirmam que as relações mercantis estão eivadas de jogos de poder, que os preços sempre refletem relações desiguais de força. Se nem no próprio seio do CJ os preços são definidos por critérios éticos e de solidariedade, mas por interesses, é realista esperar que o comércio mundial esteja livre de lutas e embates?

Subjaz ao ativismo do CJ a visão de reconstruir a ordem mundial com base nas ideias de solidariedade e justiça, numa revolução moral. Diante da presente ordenação global fundada no equilíbrio de forças - e na guerra - este ideário revela-se como um insight moral excepcional e desejável. Ele possui, com certeza, um grande valor, mas no plano da utopia e do sonho, sem efeitos práticos no atual estado das artes planetário, sendo hoje inalcançável.

O exemplo do fair trade demonstra que a crescente consciência ética, responsabilidade ambiental, e sensibilidade humana dos consumidores de classes mais abastadas, ainda que bem vindas e alavanquem efetivas e promissoras ações empresariais alternativas (além do CJ, cabe destacar também as experiências do slow food e da agroecologia), são insuficientes para modificar substancialmente o ordenamento econômico vigente. 
Apostar que a boa consciência dos consumidores do primeiro mundo, e a auto-organização dos produtores camponeses no terceiro, pode viabilizar uma outra ordem econômica internacional, equivale a acreditar que podemos mudar a direção e a velocidade de um Boeing que mergulha para a destruição pedindo aos passageiros correrem em direção oposta. Esta crença nos leva para o campo da miragem e da impostura.

O mercado, por si, não é solução para os dramas humanos modernos. Pelo contrário. Cabe inserir a atuação do CJ no mercado no âmbito dum projeto global e em forte articulação com as redes camponesas, operárias, empresariais e políticas que buscam mudar as regras do comércio internacional. O desafio hoje do CJ é recuperar a agenda do movimento terceiro-mundista dos não alinhados (donde, aliás, emergiu o movimento do CJ a partir de meados do séc. XX), renovando suas grandes consignas por um desenvolvimento alternativo, pela cooperação Sul-Sul, e por uma Nova Ordem Econômica Internacional à luz do contexto histórico contemporâneo. Pois, obviamente, a superação da pobreza e a construção de economias robustas e opulentas é uma pauta de amplitude imensamente maior que a estritamente comercial.

Não há uma história pura do CJ - e tampouco este movimento reivindica e busca tal quimera. Mas, ainda que estruturalmente o CJ sinalize a emergência dum novo padrão nas cadeias produtivas, se ele se deixar absorver por uma pauta puramente comercial e microeconômica, restringindo-se a substituir a ação política pela atuação no mercado, estará simplesmente ajustado à nova ordem globalizada do capital, reforçando seus mecanismos deletérios.

O fato do CJ não estar atrelado aos Estados (como no caso dos orçamentos participativos), e de que não cabe mais buscar uma nacionalização estatista da produção, não deve acarretar o desprezo da agenda política. Ele não deve se constituir como um substituto da mesma, pois seus efeitos serão mais amplos, duradouros e profundos se combinados com a regulação estatal, tendo, portanto, uma natureza complementar a mesma. Sem uma ação política paralela e convergente, o CJ será apenas um modesto paliativo de corte voluntarista.

Por mais amplos e fantásticos que possam ser os seus efeitos, eles praticamente ficam restritos ao âmbito dos atores e comunidades envolvidos e que teceram a prática comercial justa. Já acordos político-comerciais internacionais que permitam um relacionamento econômico mais justo entre os povos atingem ao conjunto das populações, independente tanto delas estarem mais ou menos organizadas, quanto dos humores do mercado. 


\section{REFERÊNCIAS}

SALVADOR, Anta Fonseca. "El café de sombra". In: Gaceta Ecológica, n. 80, 2006. Disponível em: 〈http://www.redalyc.org/pdf/539/53908002.pdf>.

ARANDA, Josefina. Para poder vivir: la experiencia de la CEPCO IISUABJO. In: La Jornada Ecológica, 30.08, 2004.

MONDE, Artisans du. Étude de l'impact de 25 ans de commerce équitable sur les producteurs du Sud partenaires d'Artisans du Monde. Paris, 2004. Disponível em: $\langle$ http://www.artisansdumonde.org/docs/etudeimpact.pdf >.

BARTRA, Armando. Cosechas de ira. México: Itaca, 2003.

BACON, Christopher; FLORES, Maria Eugenia. Estudio de Impacto del Sistema de Café de Comercio Justo en América Latina y el Caribe. Managua: CLAC, 2007.

BATALLA, Guillermo Bonfil. México profundo. México: Grijalbo, 1990.

CARRARO, Federica; VERDÚ, José; FERNÁNDES, Rodrigo. El rompecabezas de la equidad. Barcelona: Icaria, 2005.

COSCIONE, Marco. América Latina y el sentido originario del comercio justo. In: EUTOPÍA, n. 7, julio, 2015. Disponível em: <http://revistas.flacsoandes.edu.ec/eutopia/article/view/1633>.

COTERA, Alfonso, org. Comercio Justo Sur-Sur. Problemas y potencialidades para el desarrollo del comercio justo en la Comunidad Andina de Naciones. Lima: Grupo Red de Economía Solidaria del Perú (GRESP), 2009.

DÍAZ-POLANCO, Héctor. La diversidad cultural y la autonomía en México. Nostra Ed, 2009. Elogio de la diversidad. Siglo XXI, 2005.

ESTEVA, Gustavo. La batalla en el México rural. Siglo XXI, 1980.

FI (2015). Annual Report 2013-2014. Disponível em: <http://www.fairtrade.net/fileadmin/ user_upload/content/2009/resources/2013-14_AnnualReport_FairtradeIntl_web.pdf $>$.

HOFF, Francisco van der. Un mercado justo para el café. In: Waridel, L. et al. Un café por la causa. Hacia un comercio justo. México-Montreal: Comisión Nacional para el Desarrollo de los Pueblos Indígenas; Équiterre, 2004.

IFAT (2001). The IFAT Directory 2001/2002.

JACQUIAU, Christian. "Max Havelaar ou as ambiguidades do comércio justo". In: Le Monde Diplomatique (ed. Portuguesa), setembro, 2007.

JOHNSON, Pierre. (org.). Comércio Justo e solidário. São Paulo: Pólis, 2004a. 
. El Comercio Justo en México Sellos de Garantía y Estrategias (2004b). Disponível em: <http://facesdobrasil.org.br/articles/0029/9955/Anexo_P92_Com_rcio_Justo_M_xico_estudo_Pierre_Johnson.pdf/>.

JURADO, Silvia Nuria. Mercado internacional y pequenos productores. La UCIRI em los avatares del comercio justo. Tese doutorado em Desenvolvimento Rural. Xochimilco: Universidad Autónoma Metropolitana, 2015.

LÓPEZ R., Gilberto. México: las autonomías de los pueblos indios en el ámbito nacional. In: L. Gabriel; G. Lópes y R. (coord.). Autonomías indígenas en América Latina. Plaza y Valdes ed., 2005.

MÉNDEZ, V. Ernesto; BACON, Christopher; OLSON, Meryl; PETCHERS, Seth; HERRADOR, Doribel et. al. Effects of Fair Trade and organic certifications on small-scale coffee farmer households in Central America and Mexico. In: Renewable Agriculture and Food Systems, v. 24, n. 3, p. 236-251, 2010.

MESTRIES, Francis Benquet. El neo-zapatismo. Entre identidad ampliada y acción política estratégica. In: El Cotidiano 21 (137), 2006.

QUIJANO, Aníbal. O 'movimento indígena' e as questões pendentes na América Latina. In: Política Externa, 12 (4), 2004.

SILVA R., Evodia. Efectos locales da la producción de café alternativo en Chiapas. In: Rev. Iberoamericana de Economía Ecológica, 2006. Disponível em: <http://www.redibec.org/IVO/rev3_04.pdf>.

SYLLA, Ndongo. Fairtrade is an unjust movement that serves the rich. In: The Guardian,5.09, 2014. Disponível em: <http://www.theguardian.com/global-development/2014/sep/05/fairtradeunjust-movement-serves-rich>.

TOLEDO, Victor. El otro zapatismo. In: Ecología Política, n. 18. Barcelona: Icaria, 1999. 2006. . El dilema del zapatismo: ¿izquierdismo o sustentabilidad? En. Memoria, n. 207, Mayo,

VIVAS, Esther. ¿Comercio justo en el súper? Rebelión 20-11, 2007. Disponível em: <http://www.rebelion.org/noticia.php?id=59266>.

WARIDEL, Laure et al. Un café por la causa. Hacia un comercio justo. México-Montreal:

Comisión Nacional para el Desarrollo de los Pueblos Indígenas; Équiterre, 2004. 